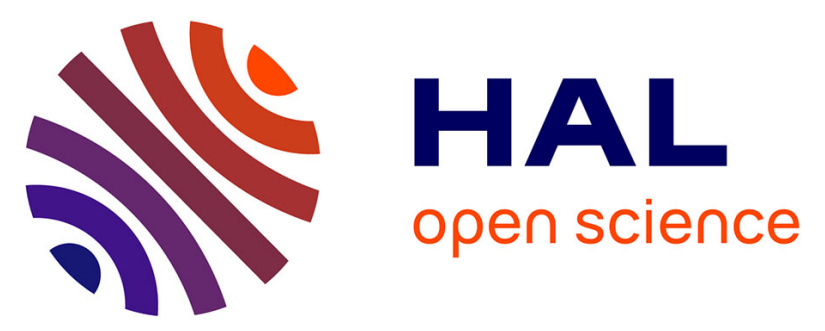

\title{
Robustness and Reproducibility of a Glenoid-Centered Scapular Coordinate System Derived From Low-Dose Stereoradiography Analysis
}

Xavier Ohl, Pierre-Yves Lagace, Fabien Billuart, Olivier Gagey, Wafa Skalli, Nicola Hagemeister

\section{To cite this version:}

Xavier Ohl, Pierre-Yves Lagace, Fabien Billuart, Olivier Gagey, Wafa Skalli, et al.. Robustness and Reproducibility of a Glenoid-Centered Scapular Coordinate System Derived From Low-Dose Stereoradiography Analysis. Journal of Applied Biomechanics, 2015, 31, pp.56-61. 10.1123/JAB.2013-0310 . hal-02472754

\section{HAL Id: hal-02472754 \\ https://hal.science/hal-02472754}

Submitted on 10 Feb 2020

HAL is a multi-disciplinary open access archive for the deposit and dissemination of scientific research documents, whether they are published or not. The documents may come from teaching and research institutions in France or abroad, or from public or private research centers.
L'archive ouverte pluridisciplinaire HAL, est destinée au dépôt et à la diffusion de documents scientifiques de niveau recherche, publiés ou non, émanant des établissements d'enseignement et de recherche français ou étrangers, des laboratoires publics ou privés. 


\title{
Robustness and Reproducibility of a Glenoid-centered Scapular Coordinate System Derived from Low-dose Stereoradiography Analysis
}

\author{
Xavier OhI, ${ }^{1,2}$ Pierre-Yves Lagacé, ${ }^{1,3}$ Fabien Billuart, ${ }^{1}$ Olivier Gagey, ${ }^{1,4}$ \\ Wafa Skalli, ${ }^{1}$ and Nicola Hagemeister ${ }^{3}$ \\ ${ }^{1}$ Arts et Métiers ParisTech; ${ }^{2} \mathrm{CHU}$ Reims; ${ }^{3 E ́ c o l e ~ d e ~ T e c h n o l o g i e ~ S u p e ́ r i e u r e ~-~ M o n t r e ́ a l ; ~}{ }^{4} \mathrm{CHU}$ de Bicêtre
}

\begin{abstract}
A robust and reproducible scapular coordinate system is necessary to study scapulothoracic kinematics. The coordinate system recommended by the ISB (International Society of Biomechanics) is difficult to apply in studies using medical imaging, which mostly use a glenoid-centered coordinate system. The aim of this study was to assess the robustness of a glenoid-centered coordinate system compared with the ISB coordinate system, and to study the reproducibility of this coordinate system measure during abduction. A Monte-Carlo analysis was performed to test the robustness of the two coordinate systems. This method enabled the variability of the orientation of the coordinate system to be assessed in a laboratory setting. A reproducibility study of the glenoid-centered coordinate system in the thorax reference frame was performed during abduction in the scapular plane using a low-dose stereoradiography system. We showed that the glenoid-centered coordinate system was slightly more robust than the ISB-recommended coordinate system. Most reproducible rotation was upward/downward rotation (x axis) and most reproducible translation was along the $\mathrm{Y}$ axis (superior-inferior translation). In conclusion, the glenoid-centered coordinate system can be used with confidence for scapular kinematics analysis. The uncertainty of the measures derived from our technique is acceptable compared with that reported in the literature. Functional quantitative analysis of the scapulothoracic joint is possible with this method.
\end{abstract}

Keywords: shoulder kinematics, coordinate system, reproducibility, stereoradiography

Scapular kinematic analysis is essential to gain a better understanding of shoulder conditions and their treatments. ${ }^{1}$ For a thorough appraisal of scapular kinematics, it is mandatory to use a robust, reproducible coordinate system based on anatomical landmarks that are identified with adequate accuracy and reproducibility. ${ }^{2}$

In 2005, the International Society of Biomechanics (ISB) elaborated recommendations in this respect, and presented the bony landmarks and the angle sequences to be used to describe the relative movements of shoulder bones. ${ }^{3}$ These recommendations describe a scapular coordinate system that is constructed from the three most easily palpable anatomical landmarks: the trigone scapulae, the inferior angle, and the acromial angle. Nevertheless, a subsequent cadaveric study ${ }^{4}$ showed uncertainties of up to $9.8 \mathrm{~mm}$ for the acromial angle. This variability in landmark identification can thus compromise the robustness of the resulting coordinate system.

With the considerable development of kinematic studies in the past decade and better access to 3D imaging techniques, scientists have proposed different types of scapular coordinate systems

Xavier Ohl, Pierre-Yves Lagacé, Fabien Billuart, Olivier Gagey, and Wafa Skalli are with Laboratoire de Biomécanique, Arts et Métiers ParisTech, Paris, France. Xavier Ohl is also with CHU Reims, Service d'OrthopédieTraumatologie, Reims, France. Pierre-Yves Lagacé and Nicola Hagemeister are with Laboratoire de recherche en Imagerie et Orthopédie-École de technologie supérieure, Centre de recherche du Centre hospitalier de l'Université de Montréal, Montréal, Canada. Olivier Gagey is also with Service de Chirurgie Orthopédique, CHU de Bicêtre, Université Paris, Le Kremlin-Bicêtre, France. Address author correspondence to Xavier Ohl at xohl@chu-reims.fr. at xohl@chu-reims.fr. based on landmarks that are not accessible via palpation but visible on the 3D models. There is therefore a growing interest in a glenoid-centered coordinate system ${ }^{5-7}$ in which the center of the coordinate system is the center of the glenoid and the axes of this coordinate system are the glenoid axes. This enables a straightforward interpretation of resulting scapular motion in terms of upward/downward rotation, internal/external rotation, and tilt. ${ }^{6}$ The robustness and reproducibility of this glenoid-centered coordinate system has, however, never been assessed, nor compared with the ISB coordinate system.

The first aim of this study was to compare the robustness of the two coordinate systems (ISB and glenoid-centered) in kinematic analysis of arm elevation in the scapular plane. For this purpose, the Monte-Carlo method was applied to both coordinate systems. A second aim was to assess the scapular kinematics of six pathological subjects and to evaluate the reproducibility of the glenoid-centered coordinate system, reconstructed three times from stereoradiography by two observers.

\section{Materials and Methods}

\section{Stereoradiography Acquisition}

This study used stereoradiographs acquired using the EOS system (EOS Imaging, Paris, France), which enables acquisition of two calibrated, low dose, orthogonal radiographs with the subject standing at a $30^{\circ}$ to $40^{\circ}$ angle of coronal rotation to the plane of one of the radiograph beams, to obtain true anteroposterior and lateral views of the scapula, and to reduce superimposition with the 
ribcage and spine. ${ }^{8}$ Seven abduction positions in the scapular plane were maintained by the subjects for 10 seconds during radiograph acquisition. Between two positions, the subjects returned to a resting position. Arm elevations were approximately $0^{\circ}, 10^{\circ}, 20^{\circ}, 30^{\circ}, 60^{\circ}$, $90^{\circ}$, and $150^{\circ}$ (positions 1-7) (Figure 1). Subjects were exposed to a radiation dose varying from $0.5 \mathrm{mGy}$ to $3.5 \mathrm{mGy}$.

First, the radiographs for one subject were used to perform a robustness study using the Monte-Carlo method. ${ }^{9}$ This method
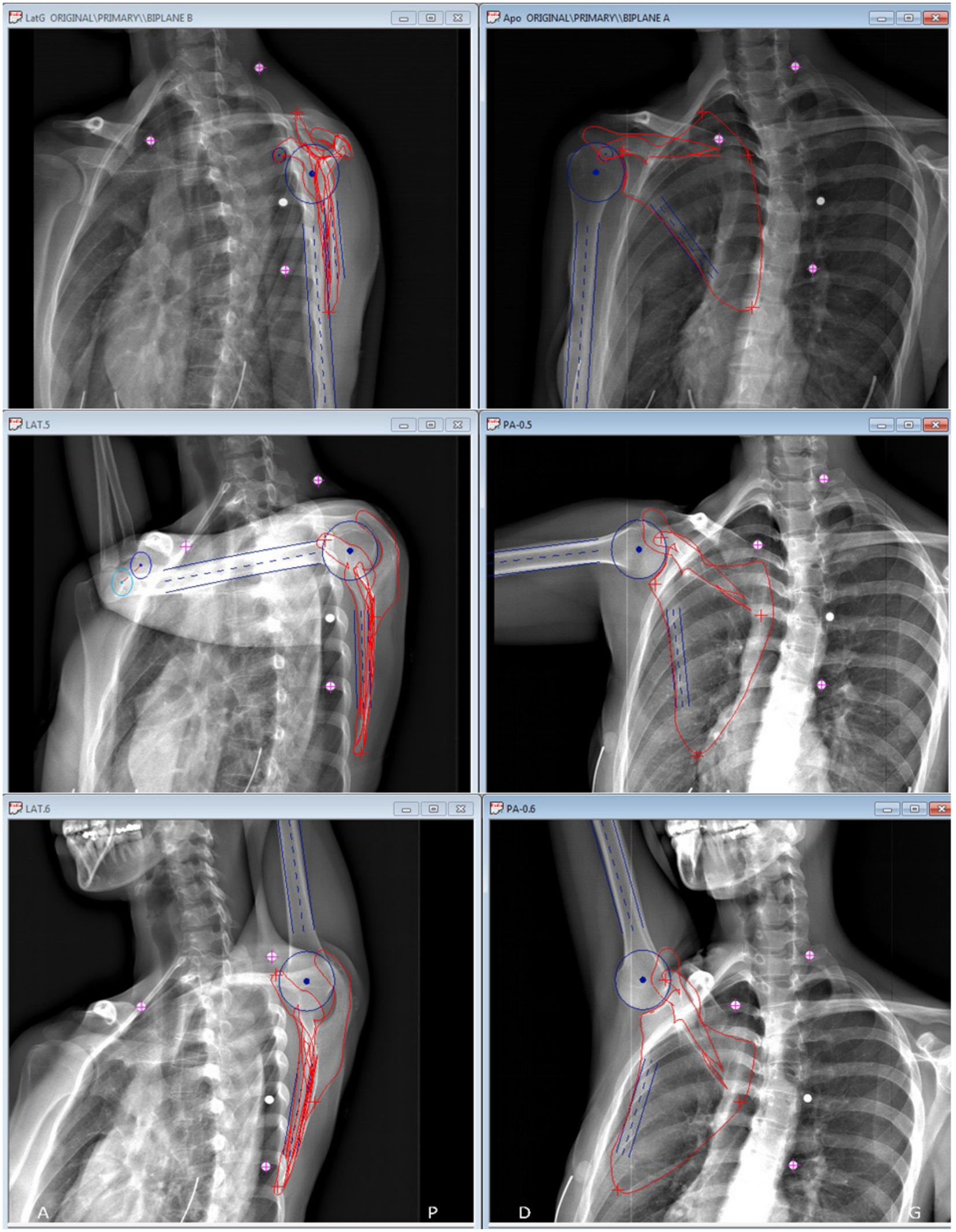

Figure 1 - Example of $3 \mathrm{D}$ reconstruction of a patient at $0^{\circ}, 90^{\circ}$, and $150^{\circ}$ abduction in the scapular plane. 
consists of simulating random errors (within known bounds) applied to the coordinate system at each position, and evaluating the variability of the orientation of the coordinate system in the laboratory coordinate system. Second, radiographs of six subjects were used to perform a reproducibility study, where two observers analyzed each subject three times.

Subjects were recruited at the university hospital from a waiting list for rotator cuff repair (mean age: 55.0 years; 2 women, 4 men; mean BMI: $26.7 \mathrm{~kg} / \mathrm{m}^{2}$ ). We used patients rather than healthy subjects to present a worst case scenario for image processing. All subjects gave their informed consent and the project was approved by the local ethics committee.

\section{Coordinate System Construction}

The thorax coordinate system was constructed in accordance with the ISB recommendations, ${ }^{3}$ based on the identification of radioopaque markers ( $6 \mathrm{~mm}$ diameter tantalum beads) which had been fixed to recommended landmarks palpated before radiograph acquisition. For the scapula, two coordinate systems were created. The first was called "ISB CS" and corresponded to the ISB recommendations, and the second, "GC CS", was glenoid-centered.

- ISB CS: Based on three bony landmarks identified on the stereoradiographs: acromial angle (AA), inferior angle (IA), and trigone scapulae (TS) according to Wu et $\mathrm{al}^{3}$ (Figure 2).

- GC CS: Based on the ellipse fitted to the glenoid rim; the origin of this coordinate system is the ellipse center. The $\mathrm{Z}$ axis was perpendicular to the least squares plane fitted to the glenoid cavity. The Ys axis was the vector between the inferior and superior borders of the glenoid, projected on the glenoid plane and oriented upward. The Xs axis was perpendicular common to Ys and Zs, oriented forward (Figure 3).

\section{Robustness of the Glenoid-centered Coordinate System Using the Monte-Carlo Method}

To study the robustness of the glenoid-centered coordinate system, the Monte-Carlo method ${ }^{9}$ was used. For the ISB CS, errors were applied to the scapular landmark coordinates used to construct the ISB coordinate system. These errors range from $0.9 \mathrm{~mm}$ to $5.1 \mathrm{~mm}$

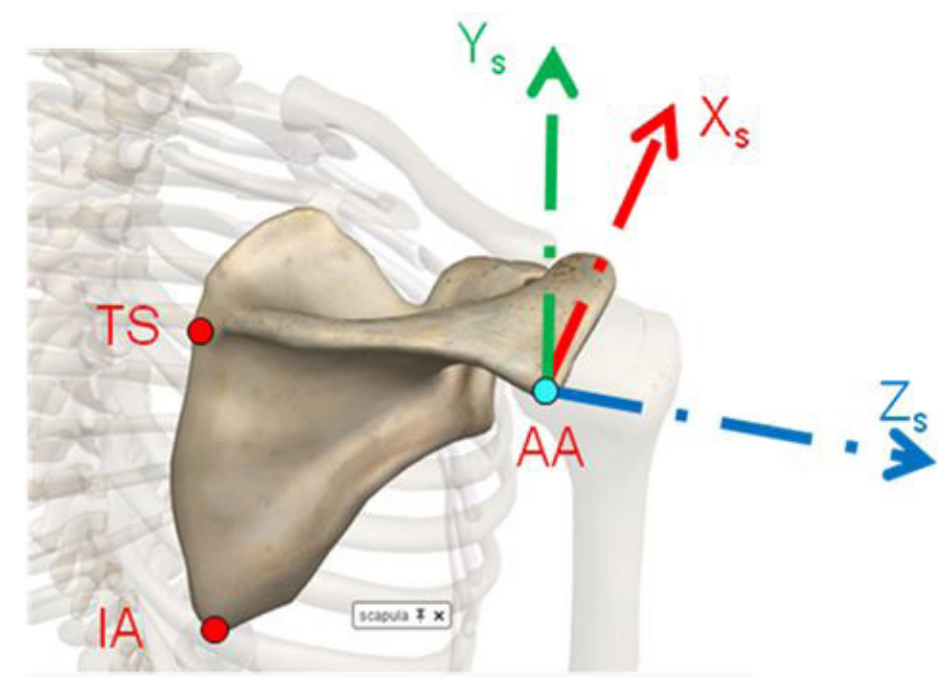

Figure 2 - Representation of the International Society of Biomechanics recommended coordinate system. (values obtained from a preliminary reproducibility study for three abduction positions in the scapular plane: $0^{\circ}, 60^{\circ}$, and $150^{\circ}$ ). For the GC CS, errors were applied to the orientation of the glenoid axes in the global coordinate system. Those errors ranged from $1.5^{\circ}$ to $4.0^{\circ}$, also obtained from the above-mentioned reproducibility study on six subjects.

These uncertainties were randomly applied to both coordinate systems to generate 100 ISB CS and 100 GC CS measures using MatLab software (The MathWorks Inc., Natick, MA).

Each scapular coordinate system was described in the thorax reference coordinate system between position 1 and positions 2 and 3. For each case, scapular orientation in the thorax coordinate system was calculated following a Y-X-Z angle sequence, and for each coordinate system, $95 \%$ confidence intervals were considered to be two standard deviations.

\section{Reliability of the Glenoid-centered Coordinate System Location}

The reproducibility study used the stereoradiographs of the six remaining subjects in seven positions $\left(0^{\circ}, 10^{\circ}, 20^{\circ}, 30^{\circ}, 60^{\circ}, 90^{\circ}\right.$, $\left.150^{\circ}\right)$. For each subject, a personalized $3 \mathrm{D}$ reconstruction of the scapula was created following the method described by Lagacé et al. ${ }^{10}$ Briefly, the observer digitizes clearly visible anatomical landmarks on both stereoradiographs for each arm position. These landmarks are used to make a first adjustment of a parameterized 3D model of the scapula. This provides a prepersonalized model of the subject's scapula. This prepersonalized model is then fitted onto each stereoradiograph corresponding to the remaining arm positions. Using additional information in these views (contours, non-stereo-correspondent landmarks, and others), the prepersonalized model is iteratively adjusted until its retroprojection most accurately fits the contours that are visible on the radiographs. This produces a 3D model of the scapula for each subject. In this model, the glenoid is parameterized by an ellipse. This ellipse is then used to construct the glenoid-centered coordinate system.

For each subject and the seven arm positions, both observers generated position and orientation measurements of the GC CS three times in the thorax coordinate system. Then, for each rotation (along the $\mathrm{Y}, \mathrm{X}$, and $\mathrm{Z}$ axis) and translation (along the $\mathrm{Y}, \mathrm{X}$, and $\mathrm{Z}$ axis), a reference measure was defined as the average of six measurements (two observers, three times). The average and maximum differences of inter- and intraobservers were calculated from this reference position.
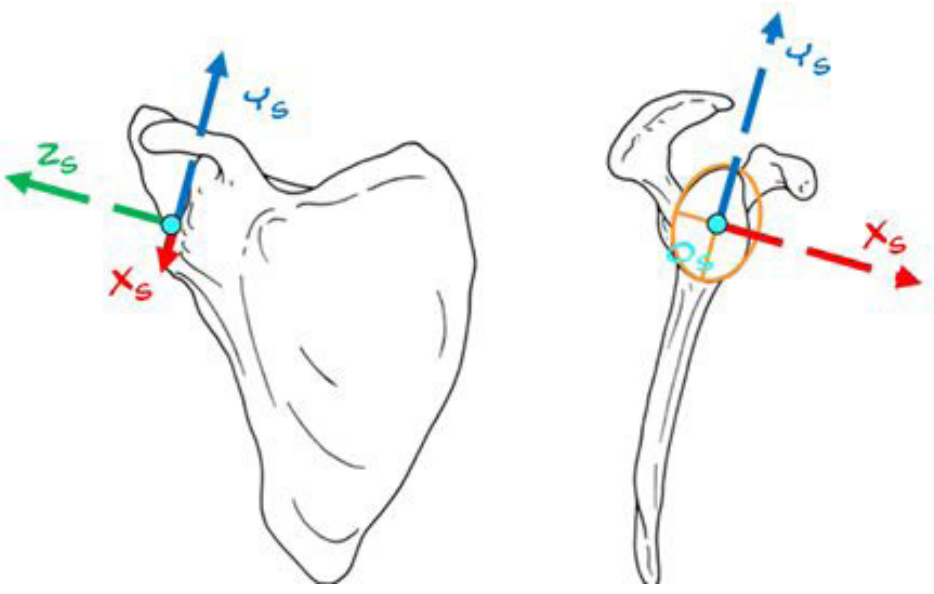

Figure 3 - Representation of the glenoid-centered coordinate system. 
The technique error is given by the root-mean-square (RMS), the $95 \%$ confidence interval was equivalent to $2 * \mathrm{RMS}$. Calculations were performed according to ISO 5725-2:1994 recommendations.

\section{Statistical Analysis}

Statistical analysis was performed using the SPSS software package (IBM Inc., Chicago, IL). For translation and rotation measures, a two-way repeated ANOVA measure was performed comparing interobserver reliability at each elevation angle (positions 1-7). Significance was set at $P<.05$.

\section{Results}

Variations in scapular orientation with the Monte-Carlo method were smaller using the GC CS than using the ISB CS (Table 1). In Table 1, angle variations ( $95 \%$ confidence interval) are presented for each position and for each coordinate system.

Scapular kinematic analysis in relation to the thorax coordinate system showed internal rotation, upward rotation, and posterior tilt (Table 2) between posture 1 and posture 7 .
Using the glenoid-centered coordinate system, the most reproducible rotation was upward/downward rotation (X axis), with a $95 \%$ confidence interval varying from $2.7^{\circ}$ to $3.6^{\circ}$. The most reproducible translation was along the $\mathrm{Y}$ axis (superior-inferior translation) with a $95 \%$ confidence interval ranging from $1.2 \mathrm{~mm}$ to $2.5 \mathrm{~mm}$ (Tables $3 \mathrm{a}$ and $3 \mathrm{~b}$ ).

Table 1 Angle variations (95\% confidence interval) for each scapular coordinate system and for each position, according to the Monte-Carlo method

\begin{tabular}{lcccc}
\hline & Humeral Elevation Angle $\left(^{\circ}\right)$ & $\mathbf{X}\left(^{\circ}\right)$ & $\mathbf{Y}\left({ }^{\circ}\right)$ & $\mathbf{Z}\left(^{\circ}\right)$ \\
\hline \multirow{3}{*}{ ISB CS } & 0 & \pm 1.4 & \pm 3.1 & \pm 2.9 \\
& 60 & \pm 2.2 & \pm 3.1 & \pm 2.6 \\
GC CS & 150 & \pm 2.5 & \pm 4.5 & \pm 3.0 \\
& 0 & \pm 2.4 & \pm 0.8 & \pm 1.6 \\
& 60 & \pm 2.7 & \pm 1.3 & \pm 2.9 \\
& 150 & \pm 2.0 & \pm 1.7 & \pm 2.0 \\
\hline
\end{tabular}

Note. ISB CS = International Society of Biomechanics coordinate system; GC CS = glenoid-centered coordinate system.

Table 2 Scapular kinematics during elevation in the scapular plane; mean ( \pm SD) translation and rotation for the six subjects

\begin{tabular}{lclc}
\hline & Mean Translation $(\mathbf{m m})$ & Mean Rotation $\mathbf{(}^{\circ}$ ) \\
\hline Along X axis & $-24.6 \pm 11.8$ (posterior translation) & Along X axis & $-44.5 \pm 6.4$ (upward rotation) \\
Along Y axis & $38.5 \pm 7.2$ (superior translation) & Along Y axis & $22.0 \pm 6.1$ (internal rotation) \\
Along Z axis & $-34.7 \pm 4.8$ (medial translation) & Along Z axis & $10.6 \pm 2.9$ (posterior tilt) \\
\hline
\end{tabular}

Table 3a Translation $\left(T_{x}, T_{y}\right.$, and $\left.T_{z}\right)$ and rotation $\left(R_{x}, R_{y}\right.$, and $\left.R_{z}\right)$ reproducibility of the glenoid centered coordinate system for positions 1-4 (mean humeral elevation angle in brackets)

\begin{tabular}{|c|c|c|c|c|c|}
\hline & & $\begin{array}{c}\text { Average Interobserver } \\
\text { Difference }\end{array}$ & $\begin{array}{c}\text { Interobserver } \\
p \text { Value }\end{array}$ & $\begin{array}{l}\mathrm{Cl} 95 \% \\
\text { (2 RMS) }\end{array}$ & $\begin{array}{c}\text { Maximum Interobserver } \\
\text { Difference }\end{array}$ \\
\hline \multirow{6}{*}{$\begin{array}{l}\left.\text { Posture } 1 \text { (mean } 13.4^{\circ}\right) \\
\text { GC CS / Thorax CS }\end{array}$} & $\mathrm{T}_{\mathrm{x}}(\mathrm{mm})$ & 1.0 & .638 & 3.0 & 3.7 \\
\hline & $\mathrm{T}_{\mathrm{y}}(\mathrm{mm})$ & 0.6 & .427 & 1.8 & 2.2 \\
\hline & $\mathrm{T}_{\mathrm{z}}(\mathrm{mm})$ & 0.9 & .582 & 2.5 & 2.3 \\
\hline & $\mathrm{R}_{\mathrm{x}}\left({ }^{\circ}\right)$ & 1.3 & $.007 *$ & 3.6 & 3.9 \\
\hline & $\mathrm{R}_{\mathrm{y}}\left({ }^{\circ}\right)$ & 1.9 & .427 & 5.2 & 6.2 \\
\hline & $\mathrm{R}_{\mathrm{z}}\left({ }^{\circ}\right)$ & 2.3 & .892 & 6.1 & 5.9 \\
\hline \multirow{6}{*}{$\begin{array}{l}\text { Posture } 2\left(\text { mean } 21.8^{\circ}\right) \\
\text { GC CS / Thorax CS }\end{array}$} & $\mathrm{T}_{\mathrm{x}}(\mathrm{mm})$ & 1.1 & .772 & 2.9 & 3.0 \\
\hline & $\mathrm{T}_{\mathrm{y}}(\mathrm{mm})$ & 0.5 & .775 & 1.2 & 1.5 \\
\hline & $\mathrm{T}_{\mathrm{z}}(\mathrm{mm})$ & 1.0 & .169 & 2.7 & 3.6 \\
\hline & $\mathrm{R}_{\mathrm{x}}\left(^{\circ}\right)$ & 1.3 & .275 & 3.5 & 3.8 \\
\hline & $\mathrm{R}_{\mathrm{y}}\left({ }^{\circ}\right)$ & 1.8 & .672 & 5.3 & 6.7 \\
\hline & $\mathrm{R}_{\mathrm{z}}\left({ }^{\circ}\right)$ & 2.3 & .440 & 5.9 & 6.0 \\
\hline \multirow{6}{*}{$\begin{array}{l}\text { Posture } 3 \text { (mean } 27.6^{\circ} \text { ) } \\
\text { GC CS / Thorax CS }\end{array}$} & $\mathrm{T}_{\mathrm{x}}(\mathrm{mm})$ & 1.4 & .234 & 4.3 & 6.4 \\
\hline & $\mathrm{T}_{\mathrm{y}}(\mathrm{mm})$ & 0.6 & .376 & 1.7 & 2.1 \\
\hline & $\mathrm{T}_{\mathrm{z}}(\mathrm{mm})$ & 1.0 & .581 & 2.9 & 3.0 \\
\hline & $\mathrm{R}_{\mathrm{x}}\left(^{\circ}\right)$ & 1.2 & .212 & 3.2 & 2.8 \\
\hline & $\mathrm{R}_{\mathrm{y}}\left(^{\circ}\right)$ & 1.9 & .616 & 5.2 & 6.9 \\
\hline & $\mathrm{R}_{\mathrm{z}}\left(^{\circ}\right)$ & 2.1 & .470 & 5.8 & 6.7 \\
\hline \multirow{6}{*}{$\begin{array}{l}\left.\text { Posture } 4 \text { (mean } 45.5^{\circ}\right) \\
\text { GC CS / Thorax CS }\end{array}$} & $\mathrm{T}_{\mathrm{x}}(\mathrm{mm})$ & 1.3 & .577 & 3.7 & 4.6 \\
\hline & $\mathrm{T}_{\mathrm{y}}(\mathrm{mm})$ & 0.4 & .307 & 1.2 & 1.4 \\
\hline & $\mathrm{T}_{\mathrm{z}}(\mathrm{mm})$ & 1.0 & .411 & 2.5 & 2.2 \\
\hline & $\mathrm{R}_{\mathrm{x}}\left({ }^{\circ}\right)$ & 1.1 & .140 & 3.2 & 3.4 \\
\hline & $\mathrm{R}_{\mathrm{y}}\left({ }^{\circ}\right)$ & 2.0 & .829 & 6.2 & 9.6 \\
\hline & $\mathrm{R}_{\mathrm{z}}\left({ }^{\circ}\right)$ & 2.1 & .792 & 5.5 & 5.0 \\
\hline
\end{tabular}

Note: $\mathrm{RMS}=$ root mean square, GC CS = glenoid-centered coordinate system; Thorax CS = thorax coordinate system.

$* P<.05$, significant interobserver difference. 
Table 3b Translation $\left(T_{x}, T_{y}\right.$, and $\left.T_{z}\right)$ and rotation $\left(R_{x}, R_{y}\right.$, and $\left.R_{z}\right)$ reproducibility of the glenoid-centered coordinate system for positions 5-7 (mean humeral elevation angle in brackets)

\begin{tabular}{|c|c|c|c|c|c|}
\hline & & $\begin{array}{c}\text { Average Interobserver } \\
\text { Difference }\end{array}$ & $\begin{array}{c}\text { Interobserver } \\
p \text { Value }\end{array}$ & $\begin{array}{l}\mathrm{Cl} 95 \% \\
\text { (2 RMS) } \\
\end{array}$ & $\begin{array}{c}\text { Maximum Interobserver } \\
\text { Difference }\end{array}$ \\
\hline \multirow{6}{*}{$\begin{array}{l}\left.\text { Posture } 5 \text { (mean } 55.7^{\circ}\right) \\
\text { GC CS / Thorax CS }\end{array}$} & $\mathrm{T}_{\mathrm{x}}(\mathrm{mm})$ & 1.2 & .622 & 3.3 & 3.8 \\
\hline & $\mathrm{T}_{\mathrm{y}}(\mathrm{mm})$ & 0.6 & .355 & 1.6 & 1.8 \\
\hline & $\mathrm{T}_{\mathrm{z}}(\mathrm{mm})$ & 1.0 & .267 & 2.9 & 3.1 \\
\hline & $\mathrm{R}_{\mathrm{x}}\left(^{\circ}\right)$ & 1.2 & .281 & 3.4 & 3.9 \\
\hline & $\mathrm{R}_{\mathrm{y}}\left({ }^{\circ}\right)$ & 2.3 & .691 & 6.5 & 7.5 \\
\hline & $\mathrm{R}_{\mathrm{z}}\left(^{\circ}\right)$ & 2.3 & .651 & 5.9 & 5.4 \\
\hline \multirow{6}{*}{$\begin{array}{l}\left.\text { Posture } 6 \text { (mean } 73.6^{\circ}\right) \\
\text { GC CS / Thorax CS }\end{array}$} & $\mathrm{T}_{\mathrm{x}}(\mathrm{mm})$ & 1.0 & .772 & 2.8 & 3.1 \\
\hline & $\mathrm{T}_{\mathrm{y}}(\mathrm{mm})$ & 0.8 & .350 & 2.5 & 2.8 \\
\hline & $\mathrm{T}_{\mathrm{z}}(\mathrm{mm})$ & 1.0 & $.038 *$ & 2.7 & 2.1 \\
\hline & $\mathrm{R}_{\mathrm{x}}\left(^{\circ}\right)$ & 1.1 & .451 & 3.3 & 4.6 \\
\hline & $\mathrm{R}_{\mathrm{y}}\left({ }^{\circ}\right)$ & 2.3 & .539 & 6.4 & 9.2 \\
\hline & $\mathrm{R}_{\mathrm{z}}\left(^{\circ}\right)$ & 2.2 & .247 & 5.9 & 6.1 \\
\hline \multirow{6}{*}{$\begin{array}{l}\left.\text { Posture } 7 \text { (mean } 131.9^{\circ}\right) \\
\text { GC CS / Thorax CS }\end{array}$} & $\mathrm{T}_{\mathrm{x}}(\mathrm{mm})$ & 0.8 & .527 & 2.5 & 3.6 \\
\hline & $\mathrm{T}_{\mathrm{y}}(\mathrm{mm})$ & 0.8 & .280 & 2.0 & 2.1 \\
\hline & $\mathrm{T}_{\mathrm{z}}(\mathrm{mm})$ & 1.1 & .335 & 3.3 & 4.6 \\
\hline & $\mathrm{R}_{\mathrm{x}}\left(^{\circ}\right)$ & 0.9 & .600 & 2.7 & 4.2 \\
\hline & $\mathrm{R}_{\mathrm{y}}\left({ }^{\circ}\right)$ & 3.0 & .843 & 8.0 & 7.8 \\
\hline & $\mathrm{R}_{\mathrm{z}}\left(^{\circ}\right)$ & 2.8 & .537 & 7.2 & 6.7 \\
\hline
\end{tabular}

Note: $\mathrm{RMS}=$ root mean square, GC CS $=$ glenoid-centered coordinate system; Thorax CS = thorax coordinate system.

$* P<.05$, significant interobserver difference.

\section{Discussion}

Our results showed that the use of a glenoid-centered coordinate system provides robust scapular orientation measurements. When uncertainties are applied to the GC CS, angular variations are mostly under $2^{\circ}$ and always under $3^{\circ}$. With our definition of robustness, we can conclude that the glenoid-centered coordinate system is highly robust. When the same Monte-Carlo method is applied to the ISB CS, variations of more than $3^{\circ}$ are observed, especially for internal/external rotation (rotation along the $\mathrm{Y}$ axis).

This can be explained by the fact that anatomical landmark definition is still difficult. Using EOS imaging system, we showed a $95 \%$ confidence interval of $11.9 \mathrm{~mm}$ for the acromial angle location ${ }^{10}$ without using 3D reconstruction. Similarly, Lewis et al performed a cadaveric study and assessed a 95\% confidence interval of $8.8 \mathrm{~mm}$ for the acromial angle location by palpation. ${ }^{4}$ Since the acromial angle is used to construct the ISB-recommended coordinate system, these uncertainties will necessarily affect the resulting kinematic calculations. The arced shape of the posterior part of the acromion is the main explanation for poor reproducibility in this location.

On the other hand, the analysis of stereoradiographs enables the location of other bony landmarks with great accuracy, such as the coracoid tip or the inferior glenoid rim. For example, on cadavers we have shown that glenoid dimensions and orientation can be defined with errors of $1^{\circ}$ and less than $1 \mathrm{~mm}$ on average with the stereographic method. ${ }^{11}$ The impact on the robustness of both coordinate systems indicates that the glenoid-centered coordinate system can be used with confidence for effective kinematic analysis of the shoulder.

Like other studies using technical imaging, we used a glenoidcentered coordinate system, ${ }^{5,7,12}$ which is based on the ellipse fitted to the glenoid rim. The origin of this coordinate system is the ellipse center and Xs and Ys are the axes of this ellipse. It is increasingly used in studies where 3D information on the glenoid is available. The center of rotation of this coordinate system is aligned with the scapular plane, which is more relevant for the clinical understanding of upward rotation (motion perpendicular to the scapular plane). ${ }^{6}$

Results on the reproducibility of the glenoid-centered coordinate system showed that scapular orientation could be obtained with a variability ranging from $2.7^{\circ}$ to $8.0^{\circ}(2 * \mathrm{RMS}, 95 \%$ confidence interval). Most reproducible rotation was upward/downward rotation and it was the least variable movement among the subjects. Tilt and internal/external rotation were less reproducible; in some cases these rotations exceed the $3^{\circ}$ of predicted reproducibility. The reproducibility of glenoid translations ranged from $1.2 \mathrm{~mm}$ to $4.3 \mathrm{~mm}(2 * \mathrm{RMS}, 95 \%$ confidence interval). Most reproducible translation was along the $\mathrm{Y}$ axis (superior/inferior translation). While interpretation of scapular translation remains difficult at this point, it is still interesting to note that the measurement of these translations is fairly reproducible.

Regarding the different techniques used to study scapular kinematics, our results are similar to those observed in the literature. Karduna et $\mathrm{al}^{13}$ assessed the accuracy of measuring 3D kinematics of the scapula with the help of magnetic tracking devices, and they showed RMS errors varying from $2.0^{\circ}$ to $9.4^{\circ}$ for scapular plane elevation. Meskers et $\mathrm{al}^{14}$ studied the intertrial variability and intraobserver reproducibility (after replacement) of an acromial skin-fixed marker. They observed high intertrial reproducibility (RMS error about $2^{\circ}$ ) but intraobserver RMS error around $5^{\circ}$. They concluded that this method could not be used for repeat studies (ie, before and after surgery).

Other techniques ${ }^{5,15}$ using CT scan and dual fluoroscopy in cadaveric condition showed great accuracy and reproducibility, with RMS errors always below $0.5 \mathrm{~mm}$ for translations and $0.5^{\circ}$ for rotations of the scapula. More recently, Zhu et al ${ }^{16}$ reported less satisfactory results in in-vivo conditions on healthy subjects using MRI 3D model and single fluoroscopy. They observed an in-plane repeatability of $\pm 0.81 \mathrm{~mm}$ and $\pm 1.77^{\circ}$ and an out-of-plane repeatability of $\pm 3.19 \mathrm{~mm}$ and $\pm 2.37^{\circ}$ for translation and rotation of the scapula, respectively. 
Mean rotations are similar to those obtained in the literature $^{13,17-19}$ except for the internal rotation, which is the most variable rotation in the literature. This can be explained by the use of symptomatic subjects, by the difference in coordinate system, and by the plane of arm elevation which seems to influence the rotation along the $\mathrm{Y}$ axis. ${ }^{20}$

The main disadvantage of the glenoid-centered coordinate system is that it necessarily needs a three-dimensional reconstruction of the glenoid. This is possible via $3 \mathrm{D}$ reconstruction of a CT scan or via stereoradiographic reconstruction using a parametric model, as proposed by Lagacé et al. ${ }^{11}$ Another disadvantage is that a glenoid-based coordinate system will be inherently influenced by glenoid version and glenoid tilt and therefore may yield results that are not consistent with a scapular-based coordinate system.

Limitations of the study include the relatively small number of subjects and the fact that we had only two observers to perform the analysis. However, it must be noted that the subjects used in this study were pathological subjects and that their stereoradiographs were taken in a real-life setting. This, to our mind, strengthens the conclusions that can be drawn from our results, since radiographs and subject positions in the EOS system were representative of what can be obtained in a clinical setting.

In summary, the glenoid-centered coordinate system can be used with confidence for scapular kinematics analysis. The uncertainty of the measures using our technique is acceptable compared with that found in the literature. Functional quantitative analysis of the scapulothoracic joint is possible with this method.

\section{Acknowledgments}

We would like to thank Guillaume Simer and Benjamin Aubert for their technical support. Funding: IRSST, ParisTech BiomecAM Chair, Société Générale and Covea.

\section{References}

1. Ludewig PM, Reynolds JF. The association of scapular kinematics and glenohumeral joint pathologies. J Orthop Sports Phys Ther. 2009;39(2):90-104. PubMed doi:10.2519/jospt.2009.2808

2. Della Croce U, Leardini A, Chiari L, Cappozzo A. Human movement analysis using stereophotogrammetry. Part 4: assessment of anatomical landmark misplacement and its effects on joint kinematics. Gait Posture. 2005;21(2):226-237. PubMed doi:10.1016/j. gaitpost.2004.05.003

3. Wu G, Van der Helm FC, Veeger HE, et al. ISB recommendation on definitions of joint coordinate systems of various joints for the reporting of human joint motion-Part II: shoulder, elbow, wrist and hand. J Biomech. 2005;38(5):981-992. PubMed doi:10.1016/j.jbiomech.2004.05.042

4. Lewis J, Green A, Reichard Z, Wright C. Scapular position: the validity of skin surface palpation. Man Ther. 2002;7(1):26-30. PubMed doi:10.1054/math.2001.0405

5. Massimini DF, Warner JJ, Li G. Non-invasive determination of coupled motion of the scapula and humerus-an in-vitro validation. J Biomech. 2011;44(3):408-412. PubMed doi:10.1016/j.jbiomech.2010.10.003

6. Ludewig PM, Hassett DR, Laprade RF, Camargo PR, Braman JP. Comparison of scapular local coordinate systems. Clin Biomech
(Bristol, Avon). 2010;25(5):415-421. PubMed doi:10.1016/j.clinbiomech.2010.01.015

7. Graichen H, Hinterwimmer S, von Eisenhart-Rothe R, Vogl T, Englmeier $\mathrm{KH}$, Eckstein F. Effect of abducting and adducting muscle activity on glenohumeral translation, scapular kinematics and subacromial space width in vivo. J Biomech. 2005;38(4):755-760. PubMed doi:10.1016/j.jbiomech.2004.05.020

8. Ohl X, Stanchina C, Billuart F, Skalli W. Shoulder bony landmarks location using the EOS low- dose stereoradiography system: a reproducibility study. Surg Radiol Anat. 2010;32(2):153-158. PubMed doi:10.1007/s00276-009-0566-Z

9. Metropolis N, Ulam S. The Monte Carlo method. J Am Stat Assoc. 1949;44(247):335-341. PubMed doi:10.1080/01621459.1949.10483 310

10. Lagacé PY, Billuart F, Ohl X, et al. Analysis of humeral head displacements from sequences of biplanar X-rays: repeatability study and preliminary results in healthy subjects. Comput Methods Biomech Biomed Engin. 2012;15(3):221-229. PubMed doi:10.1080/1025584 2.2010.522185

11. Lagacé PY, Cresson T, Hagemeister N, et al. 3D Reconstruction of the Scapula from Biplanar Radiographs. Paper presented at: Proceedings of SPIE; 23 February, 2012; San Diego, California.

12. Sahara W, Sugamoto K, Murai M, Tanaka H, Yoshikawa H. The three-dimensional motions of glenohumeral joint under semi-loaded condition during arm abduction using vertically open MRI. Clin Biomech (Bristol, Avon). 2007;22(3):304-312. PubMed doi:10.1016/j. clinbiomech.2006.04.012

13. Karduna AR, McClure PW, Michener LA, Sennett B. Dynamic measurements of three- dimensional scapular kinematics: a validation study. J Biomech Eng. 2001;123(2):184-190. PubMed doi:10.1115/1.1351892

14. Meskers CG, van de Sande MA, de Groot JH. Comparison between tripod and skin-fixed recording of scapular motion. J Biomech. 2007;40(4):941-946. PubMed doi:10.1016/j.jbiomech.2006.02.011

15. Bey MJ, Zauel R, Brock SK, Tashman S. Validation of a new modelbased tracking technique for measuring three-dimensional, in vivo glenohumeral joint kinematics. J Biomech Eng. 2006;128(4):604-609. PubMed doi:10.1115/1.2206199

16. Zhu Z, Massimini DF, Wang G, Warner JJ, Li G. The accuracy and repeatability of an automatic 2D-3D fluoroscopic image-model registration technique for determining shoulder joint kinematics. Med Eng Phys.34(9):1303-1309.

17. Bourne DA, Choo AM, Regan WD, MacIntyre DL, Oxland TR. Three-dimensional rotation of the scapula during functional movements: an in vivo study in healthy volunteers. J Shoulder Elbow Surg. 2007;16(2):150-162. PubMed doi:10.1016/j.jse.2006.06.011

18. Fayad F, Hoffmann G, Hanneton S, et al. 3-dimensional scapular kinematics during arm elevation: effect of motion velocity. Clin Biomech (Bristol, Avon). 2006;21(9):932-941. PubMed doi:10.1016/j. clinbiomech.2006.04.015

19. Ludewig PM, Phadke V, Braman JP, Hassett DR, Cieminski CJ, LaPrade RF. Motion of the shoulder complex during multiplanar humeral elevation. J Bone Joint Surg Am. 2009;91(2):378-389. PubMed doi:10.2106/JBJS.G.01483

20. Grewal TJ, Dickerson CR. A novel three-dimensional shoulder rhythm definition that includes overhead and axially rotated humeral postures. J Biomech.46(3):608-611. 